\title{
74. Vertical Crustal Displacement in the Seismic Region of Itô, on the East Coast of the Idu Peninsula.
}

\author{
By Chûji TsuboI.
}

Earthquake Research Institute, Tokyo Imperial University.

(Comm. by T. TeradA, M.I.A., June 12, 1933.)

The town of Itô and neighbourhood on the east coast of the Idu Peninsula were visited in 1930 by an unusually large number of small earthquakes." In order to ascertain whether the earth's crust of this seismic region had been deformed or not in connection with these seismic activities, precise levels were run three times in 1930 in the region along the route shown in Fig. 1. These surveys showed that the earth's crust here had upheaved in the form of an inverted $\mathrm{V}$ since the earlier surveys were made in 1923-1924. At the end of 1930 the largest upheaval amounted to as much as $220 \mathrm{~mm}$., or more, with no sign of abatement. ${ }^{2)}$

It being now two years since the last survey of 1930, urgent need was felt of running a line of levels once more over the same ground in order to measure the amount of vertical crustal displacement that must have occurred in the interval. Thanks to the generous grant given the writer by the Hattori Hôkô-kwai Foundation, he was enabled to arrange with the Military Land Survey for the work of levelling. The survey, which was begun on Dec. 25, 1932, was finished on March 16, 1933. The changes in the heights of the bench marks since the earlier survey are graphically shown in Fig. 2.

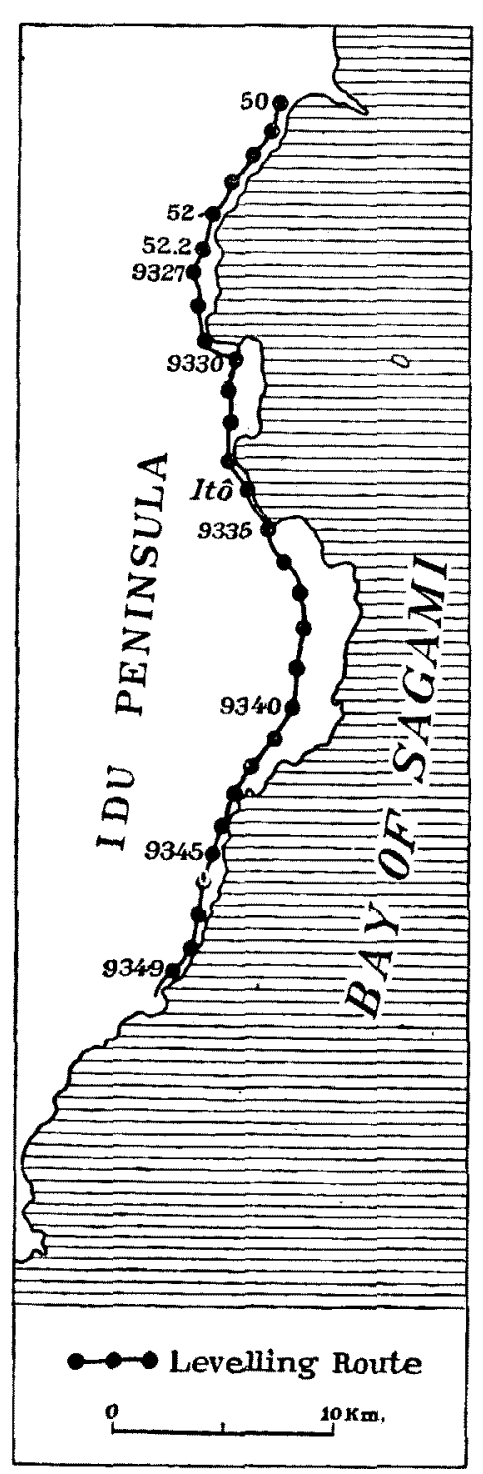

Fig. 1. Levelling Route over the Itô Seismic Region.

1) N. Nasu, F. Kishinouye and T. Kodaira: Bull. Earthq. Res. Inst., 9 (1931), 22.

2) Earthquake Research Institute: Proc. 6 (1930), 399. C. Tsuboi : Proc. 7 (1931), 153; Bull. Earthq. Res. Inst., 9 (1931), 151 ; Jap. Journ. Astr. Geophys., 10 (1933), 93. 


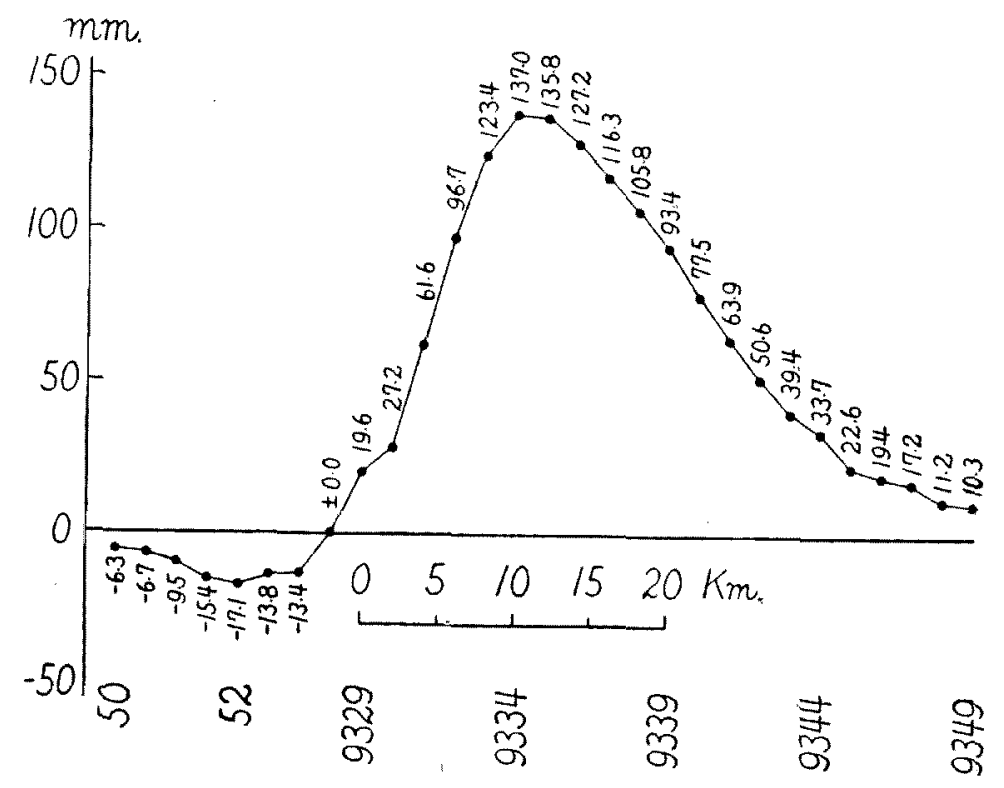

Fig. 2. Changes in the Heights of Bench Marks in the Itô Seismic Region.

Although the seismicity of the Itô region, in the two years that have elapsed since the last survey of 1930, has been quite inactive compared with that in 1930, the crustal deformation still goes on as before. It should be noted, therefore, that in the present case, there is no apparent connection between the seismic activity and the rate of crustal deformation.

Seeing that we have now the results of four series of precise levellings, all executed in the course of three years, it is possible, by simple interpolation, to find the approximate height of any bench mark in the region at any time during the interval. In making this calculation, however, the following considerations should be borne in mind.

Suppose a route is levelled on which lie bench marks $b_{1}, b_{2}, \ldots \ldots b_{n}$, and it is found that the height difference of $b_{p}$ and $b_{p+1}$ at $t_{p, p+1}$ is $h_{p, p+1},(p=1,2, \ldots \ldots n-1)$. From these data alone, however, we cannot get the height difference $h_{1, p}$ at any specified time $t$, because $t_{1,2}, t_{2,3}$, $\ldots . . . t_{n-1, n}$ are all different. Strictly speaking, we should have

$$
\begin{aligned}
& h_{1,2}(t)=h_{1,2}\left(t_{1,2}\right)+\left(t-t_{1,2}\right) \frac{\partial h_{1,2}}{\partial t}+\cdots \cdots, \\
& h_{1, n}(t)=\sum_{p=1}^{n-1} h_{p, p+1}\left(t_{p, p+1}\right)+\sum_{p=1}^{n-1}\left(t-t_{p, p+1}\right) \frac{\partial h_{p, p+1}}{\partial t}+\cdots \cdots .
\end{aligned}
$$

If, by another series of levelling over the same route, we find the values of $h_{1,2}\left(t_{1,2}^{\prime}\right) \ldots \ldots h_{n-1, n}\left(t_{n-1, n}^{\prime}\right)$, then we have, in the first approximation, 


$$
\begin{aligned}
h_{1,2}(t)= & h_{1,2}\left(t_{1,2}\right)+\frac{t-t_{1,2}}{t_{1,2}^{\prime}-t_{1,2}}\left\{h_{1,2}\left(t_{1,2}^{\prime}\right)-h_{1,2}\left(t_{1,2}\right)\right\}, \\
& \ldots \ldots \ldots \ldots \ldots \ldots \ldots \ldots \ldots \ldots \ldots \ldots \ldots \ldots \\
h_{1, n}(t)= & \sum_{p=1}^{n-1} h_{p, p+1}\left(t_{p, p+1}\right)+\sum_{p=1}^{n-1} \frac{t-t_{p, p+1}}{t_{p, p+1}^{\prime}-t_{p, p+1}}\left\{h_{p, p+1}\left(t_{p, p+1}^{\prime}\right)-h_{p, p+1}\left(t_{p, p+1}\right)\right\} .
\end{aligned}
$$

These are the expressions that give the heights of the bench marks at any particular time. The effect of the second term in the above expressions is generally assumed negligible. This is true in most cases, but in a few cases where $\left(t-t_{p, p+1}\right)$ is comparable in length with $\left(t_{p, p+1}^{\prime}-t_{p, p+1}\right)$, and where $h_{p, p+1}\left(t_{p, p+1}\right)$ differs sensibly from $h_{p, p+1}\left(t_{p, p+1}^{\prime}\right)$, the effect of the second term ceases to be negligible.

This is found to be the case with the levellings over Itô. The second levelling of 1930 was begun on Nov. 9 and finished on Dec. 3, while the third was begun on Dec. 19 and finished on Jan. 15 of the year following. The interval between the two surveys is only 16 daysshorter than the time required for the surveys themselves. In calculating the successive heights of the bench marks, therefore, the necessary reductions should be made for the effect of the second term in the above expressions. The successive heights of the bench marks that were obtained in this manner are shown in Fig. 3, in which each curve represents the height at every 100 days, beginning with April 10, 1930. The last and 11th curve, therefore, shows the height on Jan. 5, 1933.

The daily vertical velocities of the bench marks may be found from their successive heights. If the velocities are set down in parallel columns, arranged side by side in the order of time, and the same values in

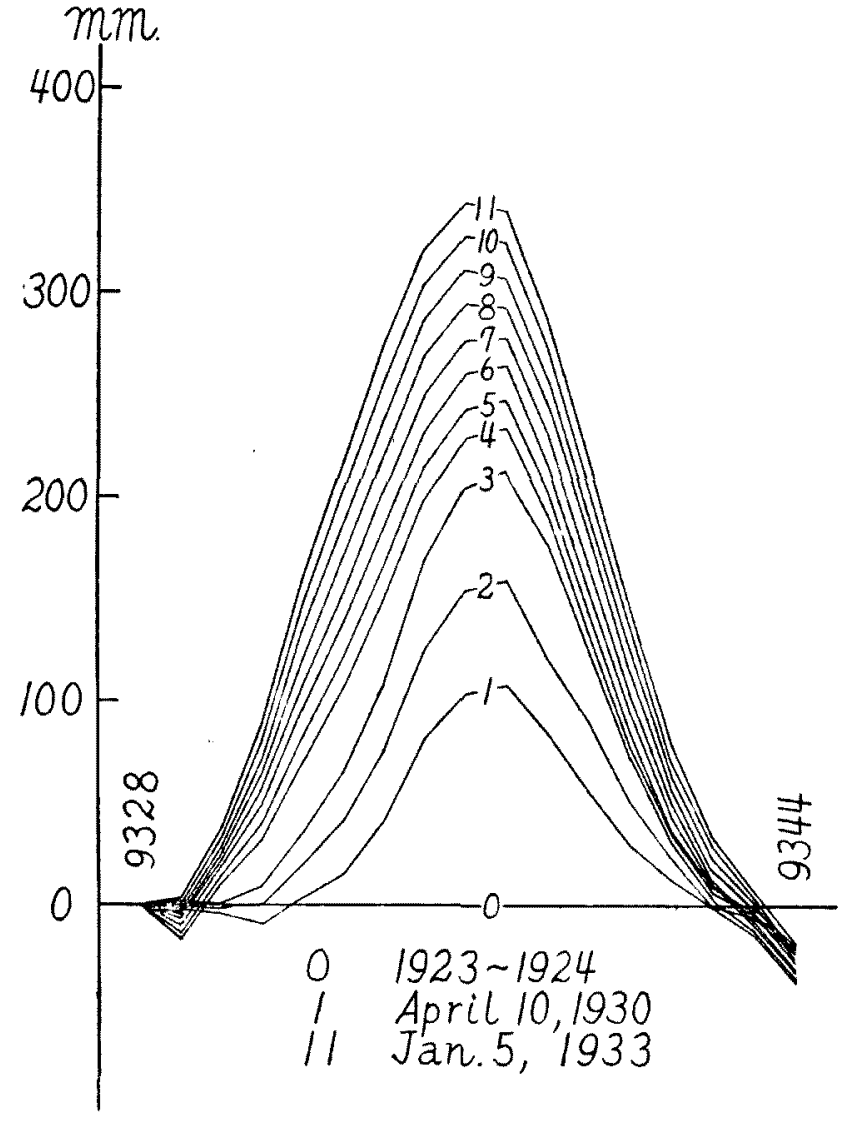

Fig. 3. Successive Heights of Bench Marks in the Itò Seismic Region at every 100 days, beginning with April 10, 1930. 


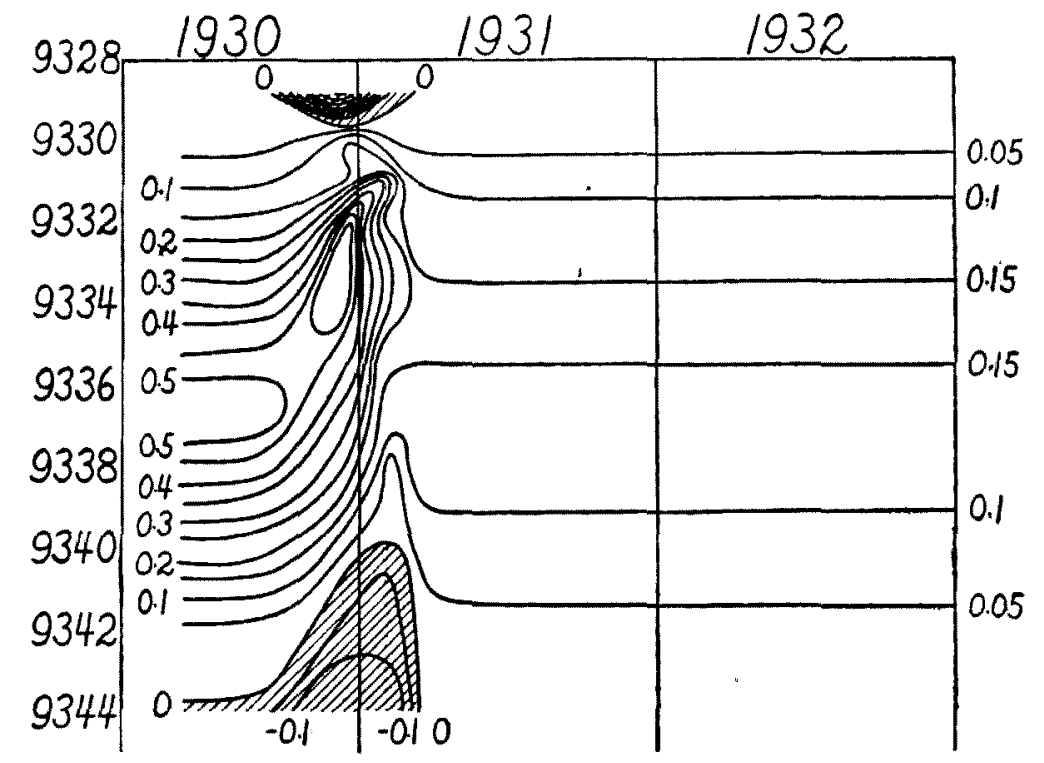

Fig. 4. Daily Vertical Velocities of Bench Marks in the Itô Seismic Region in $\mathrm{mm}$.

the different columns are joined by contour lines, we get a system of curves as shown in Fig. 4. From this figure, it is apparent that the point of largest upheaval velocity has not remained always in the same place, but has migrated northward with a monthly velocity of $1 \mathrm{~km}$. until the occurrence of the North Idu destructive earthquake of Nov. 26, 1930. After that, the point suddenly moved down southward to a new position where it remained up to the time of the last survey. After the Idu earthquake, the upheaval velocity reduced to one-half of the former values. These facts may be regarded as evidences that the equilibrium of the earth's crust at a certain place is sensibly affected even by an earthquake whose epicentre may be situated some distance away from it.

The writer wishes to express his thanks to Prof. T. Terada for his interest in this study and for his kindness in recommending the writer to the Hattori Hôkô-kwai for the grant. He wishes also to express his gratitude to the council of the Hattori Hôkô-kwai for the generous aid by means of which the survey was made possible. 